\title{
Using borehole breakouts to constrain the complete stress tensor: Results from the Sijan Deep Drilling Project and offshore Santa Maria Basin, California
}

\author{
Blair J. Zajac and Joann M. Stock \\ Seismological Laboratory, California Institute of Technology, Pasadena
}

\begin{abstract}
We use borehole breakouts in nonvertical drill holes to constrain the directions of the three principal stresses and their relative magnitudes. In this paper we start by modifying previously published breakout selection criteria to work with highly deviated borehole data. We present a forward modeling technique using genetic algorithms and a nongradient $N$-dimensional optimizer to find the best fitting stress state for a set of breakout data. The stress state is parameterized by three Euler angles and the stress state ratio $\phi$. A technique is developed to determine the $95 \%$ confidence weighted misfit between a model and the data. We then map out the $95 \%$ misfit confidence limits on the best fitting stress state. This technique is applied to data published by Qian and Pedersen [1991]. Removing their constraint of a vertical principal stress direction reduces the misfit between the stress state and the breakout data. We find that the best fitting stress state they report with a vertical principal stress direction lies outside our $95 \%$ confidence limits. We also invert breakouts in the offshore Santa Maria Basin, California. These data show a "thrust faulting" stress state with the maximum principal stress, $S_{1}$, at $N 148.5^{\circ} \mathrm{E}$ plunging $31.5^{\circ}$. The $95 \%$ confidence range for the azimuth of $S_{1}$ ranges from $\mathrm{N} 143.0^{\circ} \mathrm{E}$ to $\mathrm{N} 198.1^{\circ} \mathrm{E}$. The stress ratio $\phi$ was found to be $0.821_{0.584}^{1}$.
\end{abstract}

\section{Introduction}

Stress-induced borehole breakouts, observed on fourand six-arm dipmeter logs or acoustic televiewer logs from drill holes, are shear failures of the borehole wall that form centered at the azimuth of greatest compressive stress at the borehole wall, provided that this compressive stress exceeds the rock strength. If the borehole is vertical and aligned parallel to one of the principal stress axes, the breakouts will form at the azimuth of the far-field least horizontal principal stress, $S_{h}$. The orientation of borehole breakouts thus constrains the directions of the horizontal principal stresses $S_{h}$ and $S_{H}$. Breakout analyses in vertical holes are commonly used to determine the directions of the principal horizontal stresses, under the assumption that one of the principal stresses is vertical $\left(S_{v}\right)$. The results have been shown to be consistent with other indicators of stress direction, such as hydraulic fractures, earthquake focal mechanisms, and overcoring measurements, on both local and regional scales [e.g., Bell and Gough, 1979, 1983; Zoback and Zoback, 1980; Gough and Bell, 1981; Plumb and Hickman, 1985; Stock et al., 1985; Zoback et al., 1989; Zoback and Healy, 1992; Zoback, 1992].

Copyright 1997 by the American Geophysical Union.

Paper number 96JB03914.

0148-0227/97/96JB-03914\$09.00
Commonly, breakout data are used to constrain directions of stress but not their relative magnitudes. However, in principle, breakouts can yield information on stress magnitudes, both because the presence of a breakout indicates that the hoop stress exceeds the yield strength of the rock and because, when the borehole is not aligned with a principal stress axis, the breakout orientation depends on the relative magnitudes of all three principal stresses, as well as on the orientations of the stresses. Thus additional information about the stress tensor can be obtained from the directions of breakouts in deviated (nonvertical) drill holes; one can estimate the directions of all three principal stresses and provide some constraint on their relative magnitudes. Such a technique provides a more complete knowledge of the stress tensor and works even if none of the principal stresses is vertical.

In this paper we describe our technique of using many, differently oriented, nonvertical boreholes to constrain the principal stress directions and magnitudes of the stress tensor. The smallest data set applicable to this technique would most likely consist of a few, variably oriented wells logged with oriented caliper arm data. Offshore oil platforms provide good sources of these types of data, since the wells are drilled in many directions and at nonvertical deviations to fully develop the oil fields. Depending upon the number of wells and the horizontal extent of the caliper data, our technique 
determines a regional stress state localized over a spatial extent of kilometers to tens of kilometers.

Other authors have presented different techniques of using deviated boreholes to determine the local stress state. Qian and Pedersen [1991] applied a nonlinear inversion technique to a set of borehole breakout data. Aadnoy $[1990 \mathrm{a}, \mathrm{b}]$ examined fractures in deviated boreholes. Peška and Zoback [1995] developed a technique using leak-off tests, microfracture measurements, pore pressure measurements, breakout, and tensile fractures with theoretical borehole failure calculations to determine the stress directions and magnitudes from a single, deviated well. Neither Peška and Zoback [1995] nor the technique presented in this paper assumes a vertical principal stress direction. Multiple applications of their technique over a region would yield a more regional stress state tensor.

\section{Theory}

The theoretical basis of this technique has been recognized for nearly a decade, but it has only been applied in a few areas, perhaps because of the lack of strongly deviated drill holes in most regions. It is based on the elastic equations for stress surrounding an arbitrarily oriented cylindrical hole in a medium with known farfield stresses. Equations for the stress field surrounding a circular hole in an elastic plate subjected to plane strain are given by Kirsch [1898] and various other authors [e.g., Hubbert and Willis, 1957; Timoshenko and Goodier, 1970; Jaeger and Cook, 1979]. The equations for the stress components at the wall of a cylindrical hole in a polyaxial stress field are given by Hiramatsu and Oka [1962], Youngdahl and Sternberg [1966], Fairhurst [1968], Daneshy [1973], Richardson [1983], Mastin [1988], and Qian and Pedersen [1991].

If a drill hole is parallel to one of the principal stress directions, the rock strength and the relative magnitudes of the remaining two stresses affect the presence or absence of breakouts but not their azimuth in the borehole reference frame. The magnitudes of the principal stresses must be inferred by another technique rather than just by observations of breakout orientation.

The breakout width of the hole after breakout formation is controlled by the relative magnitudes of the principal stresses, so that if one of the principal horizontal stresses is known, and the rock strength is known or estimated, the magnitude of the other principal horizontal stress can be estimated [Moos and Zoback, 1990; Vernik and Zoback, 1992].

However, in a nonvertical hole, or a hole oriented obliquely to the three principal stress directions, one does not necessarily need independent measurements of one principal stress to infer the relative magnitudes of another principal stress, because the magnitudes of the principal stresses, as well as their directions, influence the position of the maximum compressive stress at the borehole wall [Richardson, 1983] and hence the position at which breakouts would form. This fact was further elaborated by Mastin [1988], who showed stereographic projections [Hobbs et al., 1976] indicating the direction of breakouts expected in variably oriented drill holes for different stress orientations and principal stress magnitudes. Thus, if several drill holes of different deviations are present in a given area, and if these drill holes are subject to the same stress tensor, the orientations of the breakouts in these holes may provide strong constraints on the orientations and magnitudes of the principal stresses at that location [Zajac and Stock, 1992].

To plot the breakout data from arbitrarily oriented boreholes and the calculated breakout positions for theoretical far-field stress states, lower hemisphere stereographic projections of the borehole azimuth and deviation (e.g., Figure 1) are used.

This dependence of breakout position on the far-field tectonic stress is illustrated in Figure 2, where we show patterns of breakout orientations that would be predicted for arbitrarily oriented drill holes subjected to
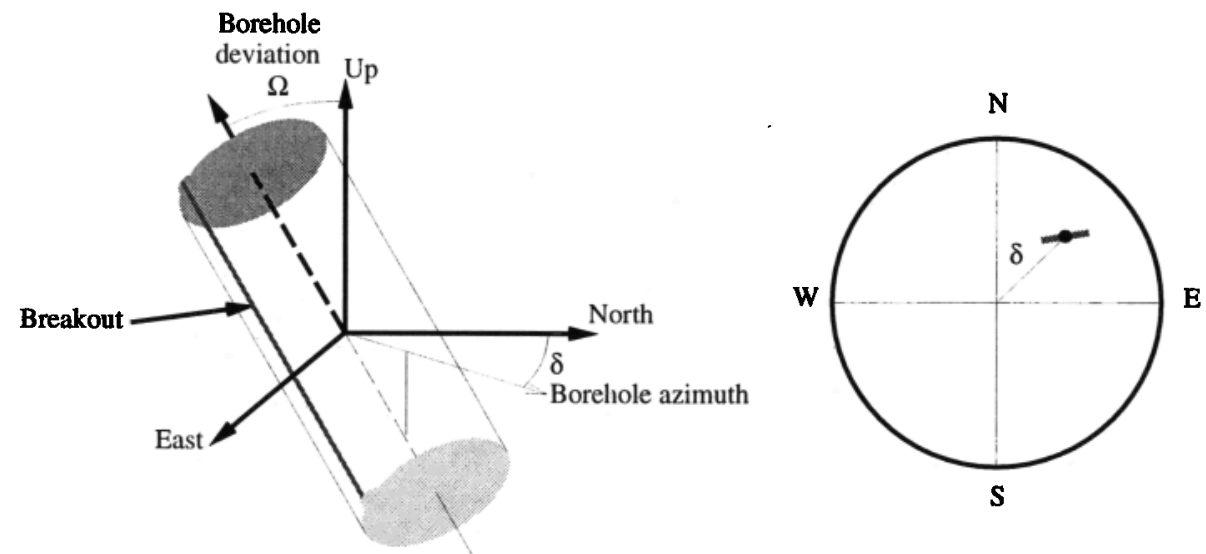

Figure 1. Relationship between an arbitrarily oriented borehole containing a breakout and how this borehole and its breakout orientation would be plotted on a lower hemisphere stereograph of borehole azimuth and deviation. 


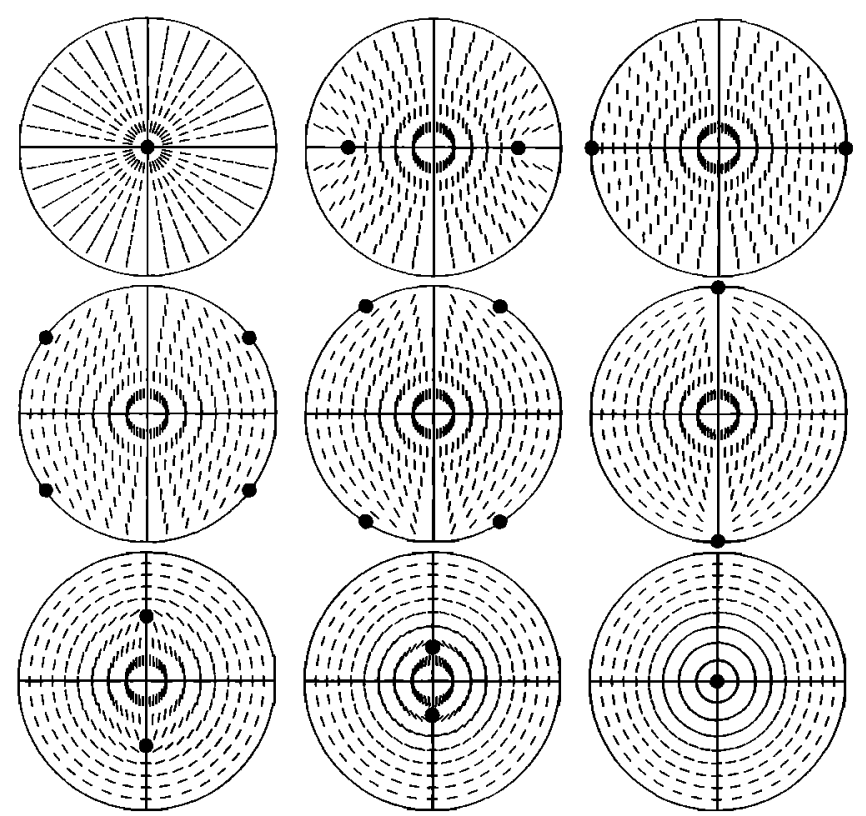

Figure 2. Relationship of breakout orientations to stress directions and magnitudes in arbitrarily oriented drill holes [Mastin, 1988]. Lower hemisphere stereographic projections show the breakout orientations, projected onto the horizontal plane, for a variety of drill hole orientations and stress regimes. Solid circles are points at which the stress anisotropy is zero and corresponds to borehole orientations with no preferred breakout direction. The low maximum compressive stress at the borehole wall at these positions indicates that breakouts might be absent. If breakouts are present near the nodal points, however, they will change orientation rapidly as borehole orientations vary. In these figures, Poisson's ratio was taken to be 0.25 , and the orientation of the maximum horizontal principal stress is always east-west for nondegenerate stress regimes. (top left) Degenerate thrust stress state, (top center) thrust regime for $\phi=0.5$, and (top right) combination of thrust and strike-slip faulting $(\phi=0)$. (middle left) Strike-slip stress regime $(\phi=0.5)$, (middle center) strike-slip stress regime $(\phi=0.8)$, and (middle right) combination of normal and strike-slip regimes $(\phi=1)$. (bottom left) Normal stress regime $(\phi=0.5)$, (bottom middle) normal stress regime $(\phi=0.2)$, and (bottom right) degenerate normal stress regime $(\phi=0)$.

certain characteristic stress fields. These are similar to the quadrant plots of Mastin [1988] and illustrate the degree to which an inversion or forward modeling of borehole breakout observations would constrain the stress regime for a given distribution of borehole orientations. The characteristic stress fields are defined by the orientations of the principal stresses $S_{1}, S_{2}$, and $S_{3}$ and the stress ratio

$$
\phi=\frac{S_{2}-S_{3}}{S_{1}-S_{3}}
$$

where $S_{1}$ is the maximum stress, $S_{2}$ is the intermediate stress, and $S_{3}$ is the minimum stress.
Note that, given enough variation in borehole orientations, the stress state can be reasonably constrained, since the patterns vary continuously from an entirely radial distribution of breakout azimuths (for degenerate thrust faulting, $S_{H}=S_{h}>S_{v}$ ) to an entirely circumferential distribution of breakout azimuths (for degenerate normal faulting, $S_{v}>S_{H}=S_{h}$ ). Here a "degenerate case" is defined when two of the principal stresses are equal in magnitude. The nodal points represent borehole orientations where circumferential stress on the borehole wall is uniform, and there is no preferred direction of breakouts; at these orientations the maximum stress at the borehole wall is relatively low and less likely to exceed rock strength, so that breakouts may be absent altogether. Note that the nodal point for degenerate thrust faulting is in the center of the projection; as the ratio of $S_{H}$ to $S_{h}$ increases, two nodal points appear and move radially away from the center along the $S_{H}$ direction. The nodal points reach horizontal at the degenerate case when $S_{h}=S_{v}$ (combined thrust and strike-slip faulting): as $S_{h}$ continues to decrease, the nodal points split again and move along the circumference of the plot. For the degenerate case of $S_{H}=S_{v}>S_{h}$ (combined strike-slip and normal faulting) the two nodal points are horizontal again and aligned along the direction of $S_{h}$; as the stress ratios progress through the normal faulting stress regime, the nodal points again approach the center of the plot.

Although in theory these patterns will vary continuously as a function of the stress regime, our ability to resolve them depends on the distribution and quality of the data, particularly on the available borehole orientations. Since few drill holes approach the horizontal, data near the nodal points for some patterns may be hard to obtain. If the boreholes within a study region are all within $30^{\circ}$ of vertical, then our ability to resolve the stress ratios will depend on the stress regime; stress ratios in normal faulting or thrust faulting stress regimes will be better resolved than those in strike-slip faulting stress regimes [Mastin, 1988]. However, in recent industry drilling programs it is common for boreholes to be deviated more than $30^{\circ}$. Our ability to resolve the stress state will also depend on the consistency of the data, since we assume that all data plotted or inverted together correspond to the same stress tensor, including both the orientations of the principal axes and the stress ratio, $\phi$.

\section{Reference Frames}

Throughout this work we use two reference frames: the geographic reference frame and the borehole reference frame (Figure 3). The geographic reference frame is an orthonormal reference frame with its $\mathbf{X}$ axis horizontal and pointing due east. The $\mathbf{Y}$ axis is also horizontal and points due north. The $\mathbf{Z}$ axis is perpendicular to both the $\mathbf{X}$ and $\mathbf{Y}$ axis and points up. This 
geographic reference frame will often be referred to as the XYZ reference frame for short.

The borehole reference frame stays aligned with the borehole axis as the borehole orientation changes with depth. So the orientation of this reference frame moves with respect to the geographic (XYZ) reference frame. The axes are named $I, J$, and $K$ and are oriented as follows. The $\mathbf{K}$ axis points up along the borehole axis, the $J$ axis is perpendicular to the $K$ axis and in the same plane as the $K$ and $Z$ axes, while $I$ is perpendicular to both the $\mathbf{J}$ and $\mathbf{K}$ axes and lies in the horizontal plane. With this definition the $\mathbf{J}$ axis always points to the high side of the hole. If the borehole is vertical, then this coordinate system coincides with the geographic coordinate system. The borehole reference frame will be referred to as the IJK reference frame for short.

Two rotations are required to rotate a coordinate system that is initially aligned with the $\mathbf{X Y Z}$ coordinate system into alignment with the IJK coordinate system. The first rotation about the $\mathbf{Z}$ axis rotates the geographic coordinate system clockwise by the angle $\delta$ till $\mathbf{X}$ coincides with $\mathbf{I}$. The resulting coordinate system will be referred as the $\xi \eta \zeta$ axes. The second step rotates the $\xi \eta \zeta$ axes about the $\xi$ axis by a counterclockwise angle $\Omega$, producing the IJK coordinate system. The two angles, $\delta$ and $\Omega$, in geological terms, are the borehole trend and deviation, respectively. See Figure 3 and equation (1).

The definition of angular measurements requires a special note for the two reference frames. We use the term "azimuth" to refer to a direction measured east from north in the geographic coordinate system. We do not use the term "azimuth" in the borehole coordinate system, since north is not a special direction in that coordinate system. Rather, all angles are measured counterclockwise from the I axis when one looks down the $\mathbf{K}$ axis. We use the word "azimuth" to refer to angles measured only in the geographic coordinate system and the word "angle" to refer to angles measured in the borehole coordinate system. When the two coordinate systems coincide, then the "azimuth" is calculated by subtracting the "angle" from $90^{\circ}$ :

$$
\text { azimuth }=90^{\circ}-\text { angle }
$$

\section{Identification of Breakouts}

Here we discuss criteria for identification of breakouts, and calculation of breakout azimuths, given either oriented four- or six-arm caliper data. Oriented four- or six-arm caliper data are measured on a variety of different well-logging tools, such as low-angle dipmeters, high-angle dipmeters, formation microscanners/microimagers, and stratigraphic high-resolution dipmeter tools (SHDTs).

Plumb and Hickman [1985] examined the validity of using four-arm dipmeters to identify borehole breakouts. They logged a well in Auburn, New York, twice with a four-arm dipmeter and once with a borehole televiewer. The borehole televiewer is an acoustic logging

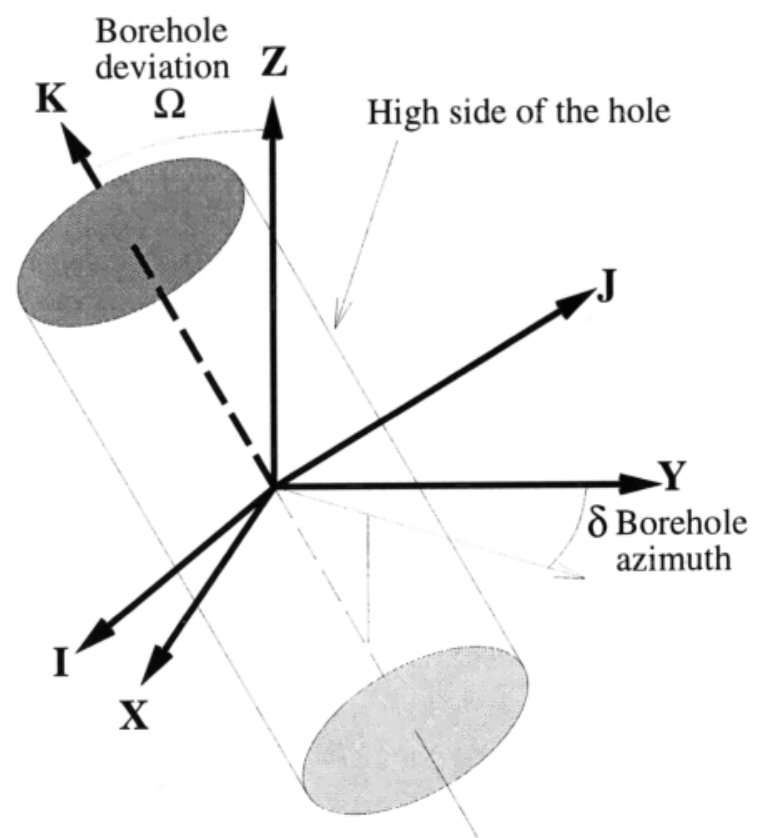

Figure 3. View of the two coordinate systems associated with the borehole. The $\mathbf{X}, \mathbf{Y}$, and $\mathbf{Z}$ axes are aligned with the geographic coordinate system. The IJK coordinate system rotates as the borehole orientation changes.

tool that provides high-resolution information about borehole elongation and the distribution of natural fractures in wells [Zemanek et al., 1970]. The acoustic transit time can be used to construct detailed borehole cross sections. By comparing the orientation of breakouts from the four-arm dipmeter with borehole cross sections constructed from the televiewer data they found that the four-arm dipmeters generally had their long axes aligned with the breakouts. This is a critical observation, since borehole televiewer logs are not commonly run in most drill holes, and many wells logged with four-arm dipmeters lack the more detailed televiewer observations.

Plumb and Hickman [1985] defined five criteria they used to identify zones of breakouts from four-arm dipmeter logs:

1. The tool rotation stops in the zone of elongation

2. The caliper arm difference is greater than $0.6 \mathrm{~cm}$.

3. The smaller of the caliper readings is close to bit size, or if the smaller caliper reading is greater than bit size, it should exhibit less variation than the larger caliper.

4. The length of the breakout zone is greater than $30 \mathrm{~cm}$.

5. The direction of elongation should not consistently coincide with the azimuth of the high side of the borehole when the hole deviates from vertical.

From our experience with examining deviated bore- 
holes we have slightly modified Plumb and Hickman's [1985] breakout selection criteria. The new criteria used are as follows:

1. The tool rotation stops in the zone of elongation. Dipmeter logs record either pad 1 azimuth or the relative bearing of pad 1 , or both. The pad 1 azimuth is the XYZ azimuth of the number 1 dipmeter pad. The relative bearing is the IJK angle between the high side of the hole and pad number 1 . Both of these measure the orientation of the tool in the hole. Our selection criterion for nondigital data sets is that the maximum variation of either measurement should be less than $10^{\circ}$. When digital data are available, the standard deviation of either data type must be less than $1.25^{\circ}$. We use Mardia's [1972] work in the statistics of angular data to calculate the average borehole elongation direction and its standard deviation for a particular section of hole.

2. The largest and smallest caliper arms should be at least $5 \%$ different from each other.

3. The smallest caliper arm should be larger than or equal to the bit size and smaller than 1.1 times the bit size.

4. The standard deviation of each caliper arm over a breakout interval should be less than $2.54 \mathrm{~cm}$ (1 inch).

5. The length of the breakout zone should be at least $3 \mathrm{~m}$.

6. The maximum difference between the bit size and the largest caliper arm should be $7.62 \mathrm{~cm}$ (3 inches).

Criterion 1 of Plumb and Hickman [1985] was tightened to be more quantitative regarding the variation in the quality of the breakout direction. Criterion 2 was changed to demand a $5 \%$ difference between the caliper arms instead of a $0.6 \mathrm{~cm}$ difference. This criterion is more flexible for boreholes of different radii. Criterion 3 was slightly changed to state that the smallest caliper arm is always as large as the bit size and no larger than 1.1 times the bit size. The minimum breakout length of criterion 4 was increased to $3 \mathrm{~m}$ to find longer, more consistent breakout intervals. Criterion 5 of Plumb and Hickman discards breakouts that fit all other selection criteria but are parallel to the high and low sides of the hole. We keep such data initially, since the theoretical breakout patterns for most stress regimes (Figure 2) show that in certain borehole orientations the breakouts are expected to be aligned with the high and low side of the hole. After initial data analysis, if we determine that some of these elongation directions are probably due to key seats, we remove them manually from the data set. We also note that Qian and Pedersen [1991] performed an inversion of a set of breakouts measured with four-arm dipmeter data containing radial breakouts (Figure 7). Finally, we add one more criterion, which discards breakouts with very large spalled regions, since other processes, such as wholesale failure along fault zones, might account for large spalled regions.

\section{Calculation of Elongation Azimuths}

Calculation of the elongation direction for a four-arm dipmeter is straightforward. We assume that the center of the dipmeter is located at the center of the borehole, so the elongation direction is parallel to the direction of the longer caliper arm. We also make the assumption that the borehole is symmetric about $180^{\circ}$, so that all elongation orientations lie between $0^{\circ}$ and $180^{\circ}$ without any loss of generality.

The six-arm dipmeter is similar to the four-arm dipmeter except that it has two extra arms and all of the arms are separated by $60^{\circ}$ intervals. Calculation of the borehole elongation direction from a six-arm dipmeter is more complicated, since it is not as obvious that any one set of caliper arms will be aligned with the breakout. In addition, the extra two pads on the borehole wall may change the threshold of detection of breakouts, because the increased friction on the borehole wall requires less ellipticity to counteract tool torque. We are not aware of any study in which the breakout directions calculated from a six-arm dipmeter have been compared to those found either from a borehole televiewer tool or from a four-arm dipmeter.

Here we describe two methods of calculating the elongation direction from six-arm dipmeter data. The first method uses the orientation of the longest caliper arm as the elongation direction. However, the longest caliper arm may not track the breakout, so the second method, which we use on our data, fits an ellipse to the caliper arm data and takes the orientation of the semimajor axis as the elongation direction.

We briefly describe the second method here. The six-arm dipmeter measures three independent diameters that are separated by $60^{\circ}$. These three values define three vectors, which originate at the origin of a suitable coordinate system and are separated by $60^{\circ}$ intervals. We assume that the three vectors constrain an ellipse centered at the origin of the coordinate system. We parameterize the orientation of this ellipse, using $\theta$, the angle between the semimajor axis of the ellipse, and the direction of caliper arm 1 (Figure 4). To determine $\theta$, we write three equations describing the ellipse, inserting the vector positions of the endpoints of the caliper arms. The three equations are then written in matrix form. As in many linear algebra problems, for a solution to exist the determinant of the matrix must be zero. Here the matrix will have zero determinant when the angle of rotation of the ellipse is found. Once this angle of rotation is found, the lengths of the semimajor and semiminor axes are easily calculated. Using this information with the rotation angle allows calculation of the elongation direction with respect to azimuth of pad 1.

One potential problem with this method is that the three caliper arm vectors might be fitted by a hyperbola instead of an ellipse. We have observed this problem with some of the data from Point Pedernales, and we choose to not select any breakouts where this happens. 


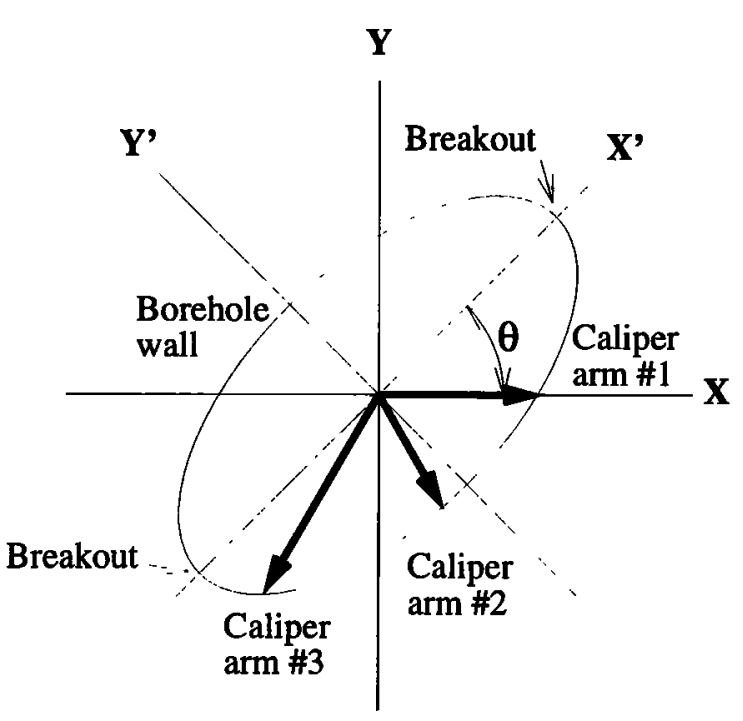

Figure 4. Geometry of the caliper arms in the six-arm dipmeter looking down onto the tool and ellipse used to find the breakout orientation.

\section{Theoretical Breakout Directions in Arbitrary Stress Fields}

Here we discuss how the theoretical breakout direction is calculated, given an arbitrary borehole orientation and far-field stress state. First, the far-field tectonic stress is transformed or rotated into the coordinate system associated with the borehole, as the stress tensor

$$
\mathbf{S}_{I J K}=\left(\begin{array}{ccc}
S_{i i} & S_{i j} & S_{k i} \\
S_{i j} & S_{j j} & S_{j k} \\
S_{k i} & S_{j k} & S_{k k}
\end{array}\right)
$$

with compressional stress positive.

Hiramatsu and Oka [1962] and Fairhurst [1968] derived the relationship between far-field stresses and stresses on the wall of a cylindrical hole, assuming that the medium is isotropic, homogeneous, and linearly elastic with constant fluid pressure in the borehole. The stresses on the borehole wall are given by

$$
\begin{aligned}
\sigma_{k k}= & S_{k k}-2 \nu\left(S_{i i}-S_{j j}\right) \cos 2 \alpha \\
& -4 \nu S_{i j} \sin 2 \alpha \\
\sigma_{\alpha \alpha}= & S_{i i}+S_{j j}-2\left(S_{i i}-S_{j j}\right) \cos 2 \alpha \\
& -4 S_{i j} \sin 2 \alpha-\Delta P \\
\tau_{k \alpha}= & 2\left(S_{j k} \cos \alpha-S_{k i} \sin \alpha\right) \\
\sigma_{1}= & \frac{1}{2}\left(\sigma_{k k}+\sigma_{\alpha \alpha}\right) \\
& +\frac{1}{2} \sqrt{\left(\sigma_{k k}-\sigma_{\alpha \alpha}\right)^{2}+4 \tau_{k \alpha}^{2}}
\end{aligned}
$$

Here, $\sigma_{1}$ is the greatest compressive stress on the borehole wall at a particular position, and $\Delta P$ is the difference between the borehole fluid pressure and the in situ pore pressure. Throughout this work we take $\Delta P$ to be 0 . The angle $\alpha$ is measured from the $I$ axis toward

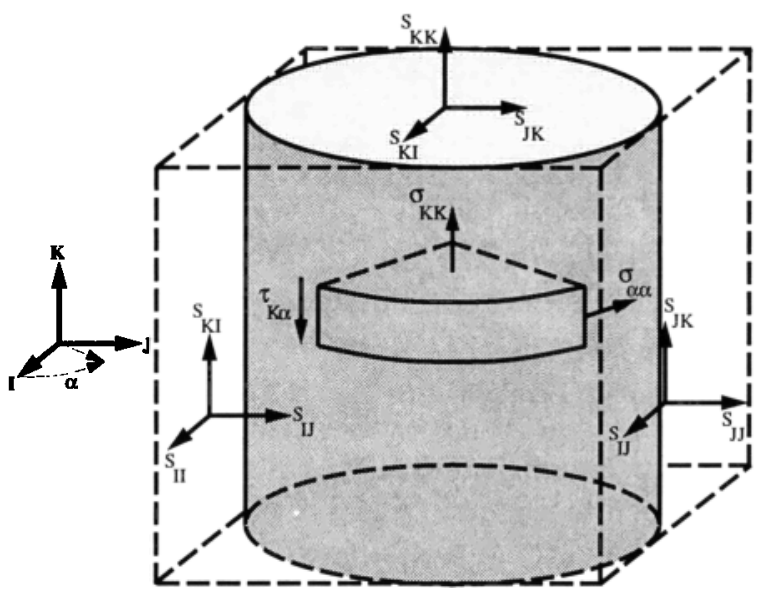

Figure 5. View of the borehole and the components of the stress tensor in the borehole coordinate system. The angle $\alpha$ is used in finding the cylindrical components of the stress tensor on the borehole wall. After Qian and Pedersen [1991].

the $\mathbf{J}$ axis (Figure 5). Here, $\nu$ is Poisson's ratio of the rock and is taken to be 0.25 . To find the position at which the breakouts should form on the borehole wall, we maximize $\sigma_{1}$ with respect to the angle $\alpha$.

\section{Inversion of Borehole Breakout Data}

In this section we describe the steps taken after a dipmeter data set is gathered to determine the stress state that best describes the data. Briefly, the steps are as follows:

1. Calculate the IJK elongation angle for all wells at $0.125 \mathrm{~m}$ depth spacing.

2. Use the breakout selection criteria listed above to identify breakouts.

3. Optionally bin the breakouts into bins of XYZ borehole azimuth and borehole deviation. We calculate a weighted average breakout direction and a weighted standard deviation of the breakout angles [Mardia, 1972]. We weight individual breakouts linearly with their length and inversely with the standard deviation of the breakout angle over the breakout's length.

4. Use a genetic algorithm (GA) to identify the region of the stress state solution space that most likely contains the minimum weighted one-norm misfit between a stress state and the, possibly binned, breakout data.

5. Run a $N$-dimensional optimizer with the results from the GA to find the minimum misfit.

6. Calculate error bounds on the best fitting stress state.

\section{Calculation of Borehole Elongation Directions}

Each data point used in the inversion consists of three values: the XYZ borehole azimuth, the borehole deviation, and IJK elongation angle. The IJK elongation angle is used in preference to the XYZ elongation az- 
imuth, because at large borehole deviations, XYZ elongation azimuths will lie predominantly $90^{\circ}$ away from the borehole azimuth. The relationship between the IJK elongation angle and the XYZ elongation azimuth is not linear, so calculation of the misfit between $\mathbf{X Y Z}$ elongation azimuths would not be representative of the real difference between IJK elongation angles.

Typically, calculating the IJK elongation angle involves several different steps depending on the types of available data. Different dipmeters measure different angular quantities recording the orientation of the dipmeter's caliper arms, either the relative bearing or the pad 1 azimuth. If the relative bearing is measured, then we subtract the relative bearing from $90^{\circ}$ to get the IJK elongation angle, since the relative bearing is measured with respect to the $\mathbf{J}$ axis. However, if the pad 1 azimuth is measured, we calculate the IJK angle that expresses the same vector direction as the pad $1 \mathrm{az}-$ imuth for the caliper arm. Depending on the age of the logging tool and the type of tool used to log the hole, we might need to make a magnetic declination correction for all geographic azimuths that the tool measures, such as the pad 1 azimuth and the borehole azimuth.

\section{Binning of Breakout Data}

After identification of the breakouts from a set of wells, lower hemisphere stereographic projection plots of the breakouts may show a large degree of scatter in the breakout angle. In this case, to simplify the subsequent inversion, we may bin the data into equalarea borehole azimuth versus borehole deviation bins. We use the technique of Mardia [1972] to calculate a weighted average and a weighted standard deviation of a set of breakout angles. We weight the data linearly with the breakout's length and inversely with the standard deviation of the IJK breakout angles over the length of an individual breakout.

\section{Stress State Parameterization}

A stress tensor can be described in a number of ways. We would like a parameterization of the stress tensor that separates the magnitudes of the principal stresses from the orientation of the principal stress directions.

We choose to parameterize the stress state with four parameters: three Euler angles and the stress state ratio $\phi$ (equation (1)). Euler angles are three angles that describe three successive rotations about various coordinate axes and are a natural representation often used to completely describe the orientation of a set of axes attached to a body in space [Goldstein, 1950]. We use this formalism to describe the orientation of the eigenvectors of a stress tensor.

Since the stress tensor is completely described by six parameters and three of the parameters describe the stress state orientation, the two parameters we are not parameterizing describe the magnitudes of the principal stresses. We can parameterize the magnitudes of the principal stress directions as

$$
\begin{aligned}
& S_{1}=a(b+1) \\
& S_{2}=a(b+\phi) \\
& S_{3}=a(b)
\end{aligned}
$$

Examination of equations (4) through (7) shows that the location of the greatest compressive stress, $\sigma_{1}$, is unaffected by the constant multiplicative factor $a$ in equations (8)-(10). Therefore the only parameter that we choose to ignore in our parameterization is $b$, which we set to 1 .

\section{Calculation of the Misfit}

In optimization of a problem a misfit scheme must be chosen that describes how well a particular model fits the data. Following Parker and McNutt [1980] and Gephart and Forsyth [1984], we use a one-norm measure of the misfit,

$$
m=\sum_{j=1}^{n} \frac{\left|\theta_{j}-o_{j}\right|}{\sigma_{j}},
$$

where $\theta_{j}$ is a theoretical value for an observation $o_{j}$ and $\sigma_{j}$ is the measure of error in the observation. We use the least absolute values $\left(L_{1}\right.$ norm) measure instead of the more familiar least squares ( $L_{2}$ norm) approach, because our data show a propensity of observations that are quite a distance away from the predicted orientations from the best fitting model. In other words, the distribution of angular differences about the best fitting model is not Gaussian, and we do not wish to weight those particular measurements as heavily as a least squares or $\chi^{2}$ misfit would do. It should be noted that the individual observations, $o_{j}$, and standard deviations, $\sigma_{j}$, appearing in equation (11) would be either the standard deviation of the IJK elongation angle over the breakout or from the statistics of the binned breakouts.

\section{Fitting the Breakout Data}

Since the determination of the best fitting stress state for a set of borehole breakout data is inherently nonlinear, we choose to use forward modeling instead of any inverse technique. Inversions have been used by others [e.g., Qian and Pedersen, 1991]. We use a two-step approach. First, a genetic algorithm [Holland, 1975; Davis, 1987; Goldberg, 1989] is applied to the problem to find an approximate best fitting stress state, using the stress state parameterization described above, consisting of the variables $(\phi, \delta, \Omega, \psi)$. Here the borehole azimuth, $\delta$, and the borehole deviation, $\Omega$, are the first two Euler angles, and $\psi$ is the third Euler angle. A $N$ dimensional optimizer is then initialized with the GAs results to find the best fitting stress state.

Genetic algorithms are an attractive approach to solving hard, nonlinear problems in which the forward calculation is straightforward but more traditional tech- 
niques might fail. Some of the advantages of GAs are that they efficiently search the problem space, do not require a good starting model, and do not get trapped in local minima (unlike gradient search methods).

GAs operate on a population of models. The models are typically binary coded, just as floating point numbers are encoded in a computer. An individual binary-encoded model is termed a chromosome. The first generation of chromosomes is randomly generated. Each chromosome has associated with it an "objective value," which is a problem-specific measure of how well the chromosome solves the problem. From the objective value is calculated a "fitness value": the higher the fitness, the better the chromosome. In our work, each chromosome represents a distinct regional stress state, and the objective value is the weighted one-norm misfit between the observed and theoretical IJK breakout angles. Since smaller one-norm misfits correspond to higher levels of fitness, we use the following equation to relate the two:

$$
f_{i}=\frac{\bar{o}+\sigma_{o}-o_{i}}{\sigma_{o}}
$$

where $\bar{o}$ is the population's mean objective value, $\sigma_{o}$ is the standard deviation of the objective values, $o_{i}$ is the $i$ th chromosome's objective value, and $f_{i}$ is the $i$ th fitness value [Holland, 1975].

After the fitness values have been calculated, chromosomes are selected to "mate" to create the next generation of chromosomes. Chromosomes with higher fitness values proportionately mate more often. Mating between two chromosomes is performed by randomly exchanging part of the binary patterns of both parent chromosomes. This operation is known as "crossover." Crossover is performed only roughly $60 \%$ of the time between two chromosomes. In the other $40 \%$ of matings the two chromosomes are carried directory into the next generation without crossover.

The final operation of the GA is mutation, whereby a small fraction of the bits of a chromosome are flipped. This process introduces variability into the population and allows broader searching of the solution space. The next generation of chromosomes has now been created, and the cycle begins anew with the calculation of the population's objective values.

We run our GAs with populations of several hundred chromosomes for several hundred generations. Since GAs do not guarantee that they find the optimal solution to a problem, we take the particular stress state corresponding to the minimum misfit observed for all of the GA runs completed as the starting point for a general $N$-dimensional optimizer routine. We use the Powell optimizer as described and coded by Brent [1973]. This particular optimizer does not require the use of derivatives of the function it is trying to optimize, a feature that makes it attractive for the borehole breakout problem.
Experience with various breakout data sets has shown that starting the Powell optimizer with a purely random stress state does not lead to a global minimum of the one-norm misfit, even for theoretically generated breakout data. The GA thus supplies an important first step in efficiently searching the space of stress states for good starting stress states for the Powell optimizer. In practice we run roughly several hundred separate GAs, each with different random numbers, to make sure we find the global one-norm misfit minimum. Even though we use the Powell optimizer after the GA, the misfit is not a smooth function of the stress state, since different GA and Powell runs find different local minima. We could have chosen to start a GA search around the results of the Powell search, but we choose not to do so, since such a search would probably not improve the results all that much.

\section{Confidence Limits}

For the results of the stress state optimization to be of any worth the confidence limits in the results must be determined. We determine the confidence limits on the best fitting stress state, using a modification of Gephart and Forsyth's [1984] technique for defining confidence limits on stress state determinations from focal mechanisms.

We want to find the $95 \%$ confidence limit on the model we obtained that minimized the one-norm misfit (equation (11)). We do this by assuming that by performing this one experiment (an experiment in the sense that oil wells were drilled and borehole breakout orientations were measured) we know something about the ensemble of one-norm misfits of the best fitting models that would result if we were able to perform the experiment again as many times as we liked. From this assumption we can say that our particular misfit lies somewhere in a probability distribution of misfits from all of the possible experiments. From this distribution of misfits we can find the misfit value, $M$, such that a certain percentage of all misfits would have misfits less than $M$. If we know that $95 \%$ of all of the misfits from these experiments have misfits $m<M$, then we have found the $95 \%$ confidence interval.

It should be stated that we are not considering the distributions of $m$ values calculated in searching for the best fitting model for our single experiment. In our single experiment the best model has an misfit $m$ at one end of a distribution of misfits corresponding to slightly different stress states. Instead, consider that when the best model for our experiment has been identified, all of the other possible stress states for the data in this experiment are ignored. Here we consider the distribution of best fitting models, or misfits, that would be found if we were able to redrill all of the holes along the same well paths and measure the breakout orientations in those new holes.

We will use the results of Parker and McNutt [1980], who calculated the statistics of the one-norm misfit, 


$$
m=\sum_{j=1}^{n}\left|x_{j}\right| / \sigma_{j}
$$

when $x_{j}$ are independent normal random variables with zero mean and standard deviations $\sigma_{j}$. The expected value of $m$ is

$$
\bar{m}=\sqrt{\frac{2}{\pi}} n \approx 0.79788 n .
$$

Parker and McNutt [1980] also wrote a program, which, given a probability $P$ and $n$, calculates the misfit $M$ such that the probability is $P$ that $m \leq M$. In other words, this program finds $M(P, n)$ such that the integral from $-\infty$ to $M$ of the one-norm distribution is $P$ for a one-norm distribution of the order of $n$. We use $M(P, n)$ later to calculate the $95 \%$ confidence limit.

To find the $95 \%$ confidence limit, we begin by defining $\sum_{\min }$ to be the minimum misfit observed in our search for the best fitting model. We then assume that this particular one-norm misfit corresponds to the mean misfit of a one-norm distribution. Of course, the mean misfit and the minimized misfit will differ, so we assume that we incorrectly estimated the errors, $\sigma_{j}$, in our misfit calculation. To correct this estimation, we introduce a new constant factor, $f$, by which we multiply all of the standard deviations, $\sigma_{j}$, such that a new misfit sum is equal to the expected misfit. Since we have already found the best fitting model to our data, we have lost $k$ degrees of freedom, where $k$ is the number of variables in the problem. We then should use the expected onenorm mean for $n-k$ observations. Mathematically, this equation becomes

$$
\sum_{m i n}=\sum_{j=1}^{n} \frac{\left|\theta_{j}-o_{j}\right|}{\sigma_{j}}
$$

from

$$
\begin{aligned}
(2 / \pi)^{1 / 2}(n-k) & =\sum_{j=1}^{n} \frac{\left|\theta_{j}-o_{j}\right|}{f \sigma_{j}} \\
& =\frac{\sum_{\min }}{f} \\
f & =\frac{\sum_{\min }}{(2 / \pi)^{1 / 2}(n-k)}
\end{aligned}
$$

Finally, to find the $P \%$ confidence misfit value, $\sum_{P}$, we use the following expression

$$
\frac{\sum_{P}}{f}=M(P, n-k)
$$

where $M(P, n-k)$ is the function given by Parker and $M c N u t t$ [1980]. We still must subtract $k$ from $n$ to find $M$, since we lost $k$ degrees of freedom in the search for the best fitting model. Solving for $\sum_{P}$, we find

$$
\sum_{P}=\frac{M(P, n-k)}{(2 / \pi)^{1 / 2}(n-k)} \sum_{\min } .
$$

Gephart and Forsyth [1984] find a similar expression in their equation (7), except they assumed that for large $n$ one can replace the one-norm inverse cumulative function $M(P, n)$ with values from standard tables of Gaussian statistics. Since we have a code that calculates $M(P, n)$, there was no reason to make this assumption.

\section{Error Analysis}

Our forward modeling approach does not give any error estimates by default, unlike other inversion methods. We determine our error bounds by varying different parameters of the best fitting stress state and evaluating how much variation is required to raise the misfit to the $95 \%$ one-norm confidence level. Because of the nature of successively rotating the principal stress directions for each Euler angle, error bounds for the Euler angles are not of much use. To see how well constrained the principal stress directions are, we fix the stress state ratio $\phi$, iterate the borehole azimuth $\delta$ from $0^{\circ}$ to $360^{\circ}$, and iterate the borehole deviation $\Omega$ from $0^{\circ}$ to $90^{\circ}$ in $1^{\circ}$ increments. This iteration rotates the $\mathrm{J}$ axis across the lower hemisphere of a stereographic plot. Since there are three error spaces, one for $S_{1}, S_{2}$, and $S_{3}$, we set $S_{j j}$ to $2, \phi+1$, and 1 . We then find the third Euler angle that minimizes the misfit. This then generates three one-norm misfit data sets as a function of $\delta$ and $\phi$, which we use to generate lower hemisphere contour maps of the $95 \%$ confidence misfits for the $S_{1}, S_{2}$, and $S_{3}$ axes.

When we vary the stress state ratio $\phi$ away from the minimum misfit and make the lower hemisphere contour plots of the $95 \%$ confidence misfit, we observe smaller enclosed $95 \%$ contour regions that are sometimes rotated away from their minimized locations.

\section{Analysis of Qian and Pedersen's Borehole Breakout Data}

As one test of our technique we reanalyze the borehole breakout data presented by Qian and Pedersen [1991] from the Sijan Deep Drilling Project in Sweden. The data are taken from Table 3 of Qian and Pedersen [1991] and are plotted in Figure 6. This table lists a depth range and the average borehole azimuth, deviation, and breakout orientation for that range. Also listed is the variance of the breakout direction in degrees over that interval. Figure 7 plots a histogram of the angular differences between the location of the high side of the borehole and the breakout angle as measured in the plane perpendicular to the borehole axis for all of the data. We see that the breakouts are clustered around the high side of the hole and could possibly be due to tool drag. Since we do not have the original caliper curves, we cannot apply our breakout selection technique to this data set, and we use the data set unmodified.

Qian and Pedersen [1991] applied a nonlinear inversion technique to their data, assuming a vertical prin- 


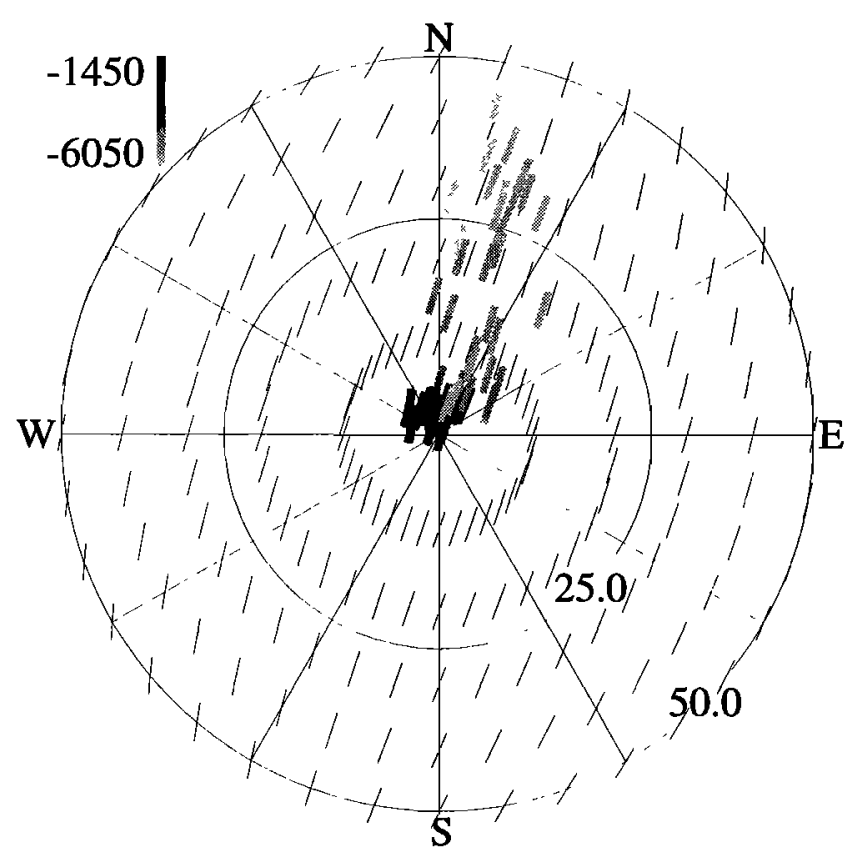

Figure 6. Compiled and processed data from the Sijan Deep Drilling Project in Sweden from Qian and Pedersen [1991] plotted on top of the theoretical breakout pattern for their best fitting stress state of $S_{H} / S_{v}=$ $1.2_{1.05}^{\infty}$ and $S_{h} / S_{v}=0.6_{0.0}^{0.98}$, where $S_{H}$ lies $108.4_{108.0^{\circ}}^{\circ 108.7^{\circ}}$ east of north. The nodal points for this stress state lie at a deviation of $90^{\circ}$; hence they do not show in this plot. A Poisson's ratio of 0.25 was used to calculate the breakout pattern. The vertical depth scale is in meters.

cipal stress direction with Poisson's ratio, $\nu$, equal to 0.25. They found the stress state to be a strike-slip regime $\left(S_{H}>S_{v}>S_{h}\right)$ with the maximum horizontal stress located $108.4_{108.0^{\circ}}^{\circ 108.7^{\circ}}$ east of north. The ratio of stresses was $S_{H} / S_{v}=1.2_{1.05}^{\infty}$ and $S_{h} / S_{v}=0.6_{0.0}^{0.98}$, which corresponds to a stress ratio $\phi$ of $2 / 3$. The error bounds listed here are nonlinear error bounds calculated by varying the stress parameters until a large enough misfit was observed.

In Figure 6 we plot Qian and Pedersen's [1991] data with the theoretical breakout pattern expected for the stress state resulting from their inversion. A Poisson's ratio of 0.25 was used in this calculation. The data show almost constant breakout azimuths regardless of the borehole orientation. Because of the relatively restricted range of borehole azimuths present in their data a large number of nondegenerate normal and strike-slip faulting stress regimes could fit their observations with nearly constant breakout orientations up to the maximum deviation of $45^{\circ}$ (Figure 2). In this case the data are not well distributed in order to constrain the complete stress tensor. Qian and Pedersen's [1991] high uncertainty in the $S_{h} / S_{v}$ ratio reflects exactly this problem with the data distribution. This will be a common problem in strike-slip stress regimes if highly deviated holes are not available. The only way to remedy this is to either find or drill boreholes that are nearly horizontal.

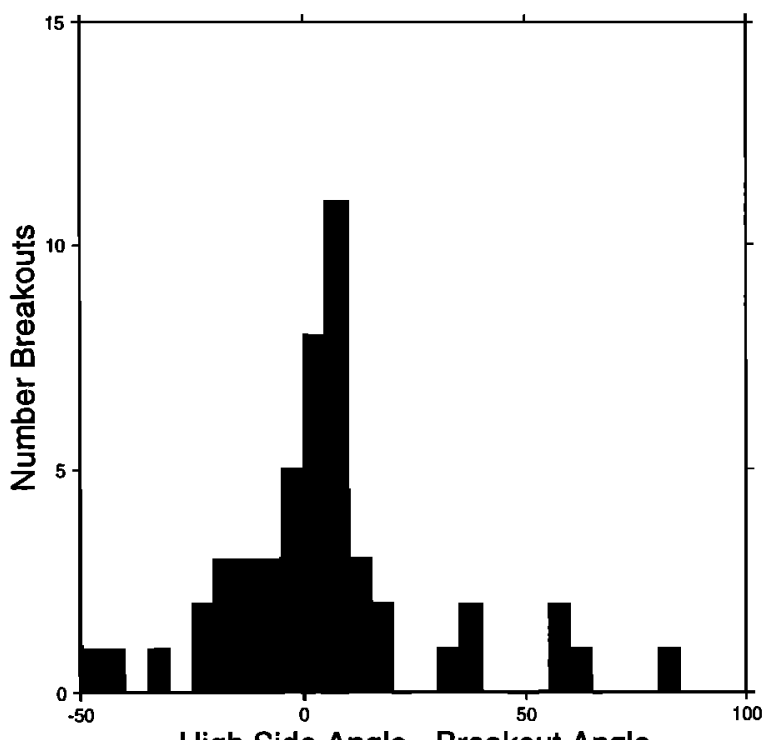

High Side Angle - Breakout Angle

Figure 7. Histogram of the angular difference measured in the plane perpendicular to the borehole axis between the breakout orientation and the high and low sides of the borehole for the Qian and Pedersen [1991] data.

To compare the inversion technique of Qian and Pedersen [1991] with the genetic algorithm and Powell optimizer technique described above, we "inverted" their data set, using our technique. The data set was not gridded, since it shows a large amount of consistency. The breakout data are best described by a thrust faulting stress state in which $S_{1}$ is oriented $N 106.8^{\circ} \mathrm{E}$ plunging 3.5. $S_{2}$ is also almost horizontal, oriented $N 16.7^{\circ} \mathrm{E}$, plunging $2.5^{\circ}$. Finally, $S_{3}$ is almost vertical, plunging $85.7^{\circ}$ at an azimuth of $N 251.7^{\circ} \mathrm{E}$ (Table 1 ). The $\phi$ value for our solution is 0.40 .

Error bounds on our stress state determination are shown in Figures 8 and 9. Figure 8 shows contour plots of the $\mathbf{9 5 \%}$ confidence misfits for the three principal directions on a lower hemisphere stereographic projection keeping $\phi$ constant. The direction of $S_{1}$ is very tightly constrained, but the orientations of $S_{2}$ and $S_{3}$ are almost unconstrained about an arbitrary rotation about the $S_{1}$ axis.

In Figure 9 we plot the 95\% confidence limit (thick solid line), the weighted one-norm misfit as a function of $\phi$ using the Euler angles from the best fitting model

Table 1. Characteristics of the Stress State That Minimized the Weighted One-Norm Misfit of the Qian and Pedersen [1991] Borehole Breakout Data

\begin{tabular}{llll}
\hline & $S_{1}$ & $S_{2}$ & $S_{3}$ \\
\hline Azimuth & $\mathrm{N} 106.8^{\circ} \mathrm{E}$ & $\mathrm{N} 16.7^{\circ} \mathrm{E}$ & $\mathrm{N} 251.7^{\circ} \mathrm{E}$ \\
Plunge & $3.5^{\circ}$ & $2.5^{\circ}$ & $85.7^{\circ}$ \\
Value & 2 & 1.40 & 1 \\
\hline
\end{tabular}

Optimized $\phi, 0.40_{0.00}^{1.00} ;$ minimum weighted one-norm misfit, $1.71^{\circ} ; 95 \%$ confidence level for weighted onenorm misfit, $2.03^{\circ}$. 


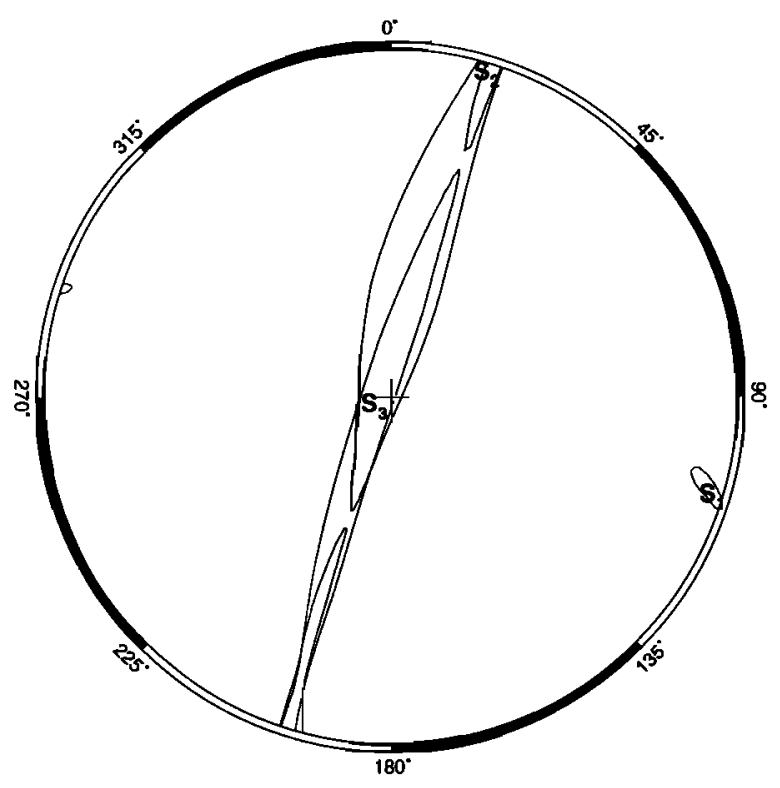

Figure 8. Results from the reanalysis of the Qian and Pedersen [1991] borehole breakout data using our GA and Powell optimization technique. Lower hemisphere stereographic projection shows contours of the $95 \%$ weighted one-norm misfit confidence limits for the three principal stress directions. The stress state ratio $\phi$ is held constant at 0.40 . Note that the direction of $S_{1}$ is very well constrained, but $S_{2}$ and $S_{3}$ can lie virtually anywhere within a vertical plane striking $N 16.7^{\circ} \mathrm{E}$.

(dotted line), and the weighted one-norm misfit allowing the Euler angles to vary to minimize the misfit for a particular $\phi$ (thin solid line). The plot demonstrates that the stress ratio $\phi$ is unconstrained, since there exists a stress state that can be rotated in such a way to fit the borehole breakout data within the $95 \%$ confidence limits for any $\phi$. We have created lower hemisphere stereographic projection plots of the $95 \%$ confidence misfit for nonoptimal $\phi$ values. These plots do not show any smaller confidence regions, a finding that is not surprising given that the minimum misfit as a function of $\phi$ is almost constant. Given the sparseness of the borehole orientations sampled by these data, the lack of constraint on $\phi$ is not surprising. However, the stress states that fit the data for any $\phi$ may not have a principal stress direction anywhere near vertical, so the mathematics of this fit does not take into account some of the geophysics of the problem.

The orientation of $S_{H}$ determined by Qian and Pedersen [1991] and determined in this paper differ by only $1.6^{\circ}$. However, the remaining components of the stress state differ considerably. Qian and Pedersen [1991] found a strike-slip stress state with $\phi=2 / 3$. We found a thrust faulting stress state with $\phi=0.40$. The stress direction contour map (Figure 8) also shows that $S_{2}$ and $S_{3}$ may be allowed to rotate almost freely about the $S_{1}$ axis, thereby switching from a thrust faulting to a strike-slip environment. This finding is consistent with the observation that nondegenerate thrust and strike-slip faulting stress regimes can have very similar,

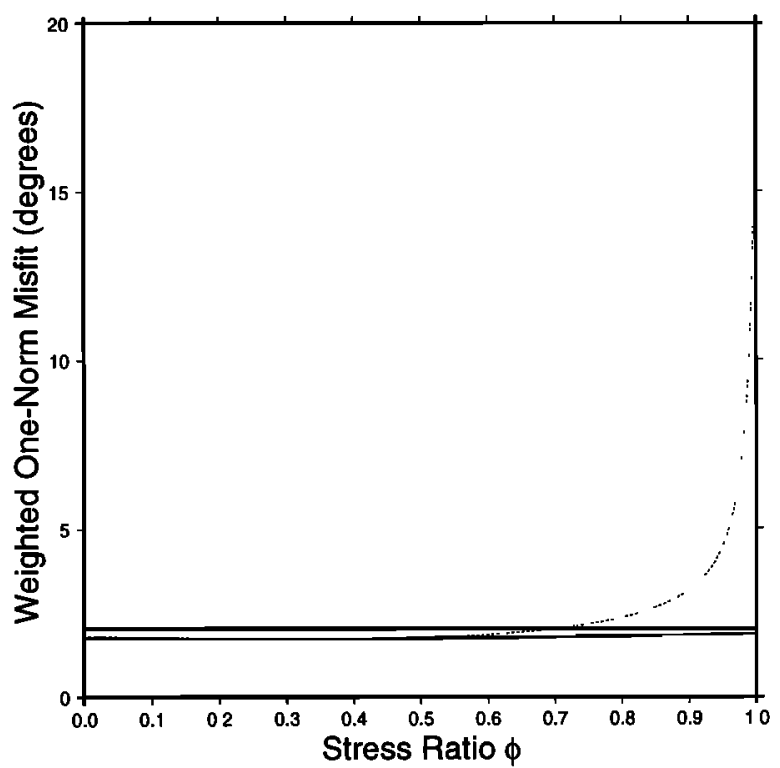

Figure 9. Results from the reanalysis of the Qian and Pedersen [1991] borehole breakout data. Plot of the weighted one-norm misfit as a function of $\phi$, where the thick solid line is the $95 \%$ confidence limit $\left(2.03^{\circ}\right)$, the thin solid line is the minimized misfit when $\phi$ is held constant and the principal stress directions are unconstrained, and the dotted line is the misfit using the principal stress directions from the best fitting model.

nearly constant, breakout orientations for small deviations (Figure 2). Qian and Pedersen [1991] state that their inversion clearly shows a strike-slip stress regime. We feel that their conclusion is too strong, given their breakout data and the analysis presented here.

Qian and Pedersen [1991] also state that it is not feasible to relax the assumption of a vertical principal stress direction given their analysis of inversions of theoretical breakout data. However, there are several reasons why stress states with nonvertical principal stresses should be considered. First, the extra degree of freedom gives a clearer sense of how poorly or well constrained the stress state is from Qian and Pedersen's [1991] data. Second, it allows a much better fit of the data. The weighted one-norm misfit of the data using Qian and Pedersen's [1991] best fitting stress state is $2.15^{\circ}$, which is outside our $95 \%$ confidence limit of $2.03^{\circ}$. Finally, there might be some breakout data sets in which the assumption of a vertical principal stress direction is invalid, leading to an improper understanding of a region's stress state. The cost of this extra degree of freedom is slight in comparison with the potential gain in understanding of stress states.

\section{Borehole Breakouts in Point Pedernales, California}

We applied our technique to determine the stress state in the offshore Santa Maria Basin, California, from wells drilled by the Unocal Company from an offshore platform in the Point Pedernales Oil field (Figure 10). 


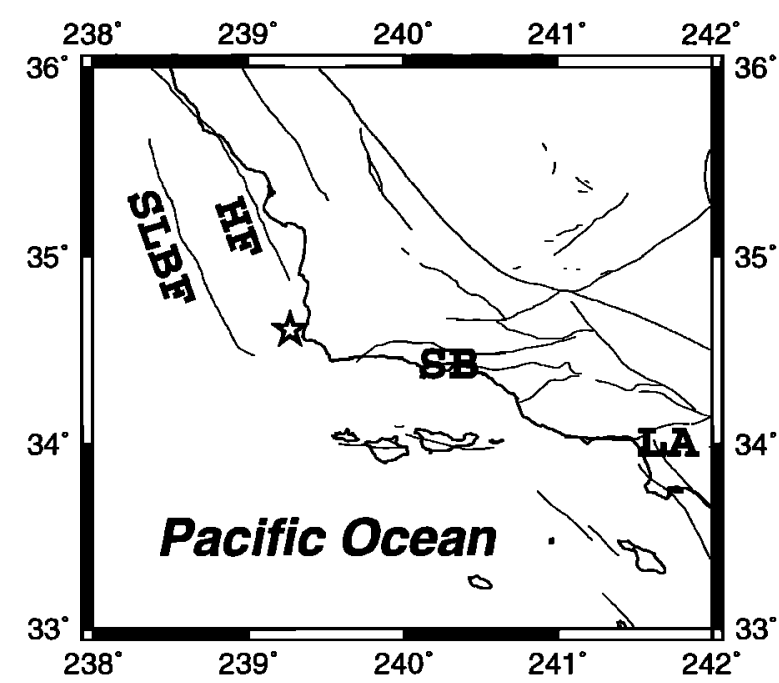

Figure 10. Location (star) of the Point Pedernales field in the offshore borderland along with some of the major Quaternary faults in the southern California region. LA, downtown Los Angeles; SB, Santa Barbara; SLBF, Santa Lucia Bank Fault; and HF, Hosgri Fault.

The offshore Santa Maria Basin is an elongated, structural basin parallel to the California coast northwest of Point Arguello [McCulloch, 1987]. It lies between two NNW trending structural boundaries: a zone of east dipping normal faults, including the Santa Lucia Bank fault, on the west side, and the Hosgri fault on the east side. However, it appears to be stratigraphically continuous with the onshore Santa Maria Basin, east of the Hosgri fault, and to have experienced a similar Miocene deformational history [Sorlien, 1994].

The basal Tertiary section in the offshore Santa Maria Basin comprises volcanic rocks of probable early Miocene age which rest on basement and have been displaced by normal faults [McCulloch, 1987]. This volcanism and a subsequent phase of subsidence 18-16 Ma, documented by use of backstripping techniques in several wells in the region, have been attributed to the capture of the Monterey microplate by the Pacific plate [Sorlien, 1994] and the beginning of clockwise rotation of the Western Transverse Ranges [McCrory et al., 1995]. This development was followed by slow thermal subsidence from $\sim 16$ to $\sim 7 \mathrm{Ma}$ [McCrory et al., 1995]. Since $6 \mathrm{Ma}$ the tectonics of this offshore region has been locally complicated because of an overall transpressional regime, which produced NE-SW directed shortening between 5 and $3 \mathrm{Ma}$ and much slower deformation in Quaternary time [e.g., Clark et al., 1991; Crouch et al., 1984].

Unocal provided us with five paper logs of four wells from the Point Pedernales field. All four wells were drilled from the same platform and all of the dipmeter data lies within a $4.3 \mathrm{~km}$ radius of the platform. Table 2 lists the type of tool used to log the hole and some of the properties of the wells, including the logged depth interval, the depth interval of processed dipmeter data, and the maximum deviation of the well over the processed interval.

To analyze the well log data for the ambient tectonic stress, we ran the raw dipmeter data through a series of steps. The steps were as follows:

1. Digitize the paper logs and resample them to $0.125 \mathrm{~m}$ intervals.

2. Apply caliper calibration corrections to the caliper arm data for those wells in which the well log shows a caliper correction.

3. Compare the dipmeter's borehole azimuth data with the data from an independent directional survey of the hole (single-shot deviation surveys or gyroscopic logs). If the two data sets differ by roughly the magnetic declination $\left(15^{\circ} \mathrm{E}\right.$ for this location), then apply the declination correction to the dipmeter's borehole azimuth and pad 1 azimuth data. We applied the declination correction to A-1 and A-7. The data from A-13 and A-16 agreed with their directional surveys to within $5^{\circ}$ and hence were not further corrected.

4. Calculate the borehole elongation direction, using the four- and six-arm technique described above. These data are plotted at every meter in Figure 11 as lower hemisphere stereographic projections of the bore-

Table 2. Digitized well logs from the Unocal Company of Wells Drilled Offshore From Point Pedernales, California, in the Santa Maria Basin

\begin{tabular}{|c|c|c|c|c|}
\hline Well Name & Log Type & $\begin{array}{l}\text { Logged Depth } \\
\text { Interval, m }\end{array}$ & $\begin{array}{l}\text { Processed True Vertical } \\
\text { Depth Interval, m }\end{array}$ & $\begin{array}{r}\text { Maximum } \\
\text { Deviation }\end{array}$ \\
\hline$\overline{A-1}$ & $\begin{array}{l}\text { Gearhart four electrode } \\
\text { dipmeter survey }\end{array}$ & $\begin{array}{l}710-1788 \text { logged } \\
715-1784 \text { processed }\end{array}$ & $605-1672$ & $7.0^{\circ}$ \\
\hline A-7 & $\begin{array}{l}\text { Gearhart six electrode } \\
\text { dipmeter }\end{array}$ & $\begin{array}{l}732-2226 \text { logged } \\
733-2197 \text { processed }\end{array}$ & $686-1802$ & $45.1^{\circ}$ \\
\hline A-13 Log1 & $\begin{array}{l}\text { Schlumberger SHDT } \\
\text { monitor log }\end{array}$ & $\begin{array}{l}1729-2284 \text { logged } \\
1730-2288 \text { processed }\end{array}$ & $969-1088$ & $80.5^{\circ}$ \\
\hline A-13 Log2 & $\begin{array}{l}\text { Schlumberger dipmeter } \\
\text { monitor log }\end{array}$ & $\begin{array}{l}2300-2606 \text { logged } \\
2301-2497 \text { processed }\end{array}$ & $1092-1138$ & $79.7^{\circ}$ \\
\hline A-16 & $\begin{array}{l}\text { Schlumberger formation } \\
\text { microscanner log }\end{array}$ & $\begin{array}{l}2643-4267 \text { logged } \\
2646-4201 \text { processed }\end{array}$ & $1008-1254$ & $89.6^{\circ}$ \\
\hline
\end{tabular}

For well A-13 we received two separate paper logs. "Logged depth" is measured along the well bore but is greater than the true vertical depth where the borehole is deviated. 


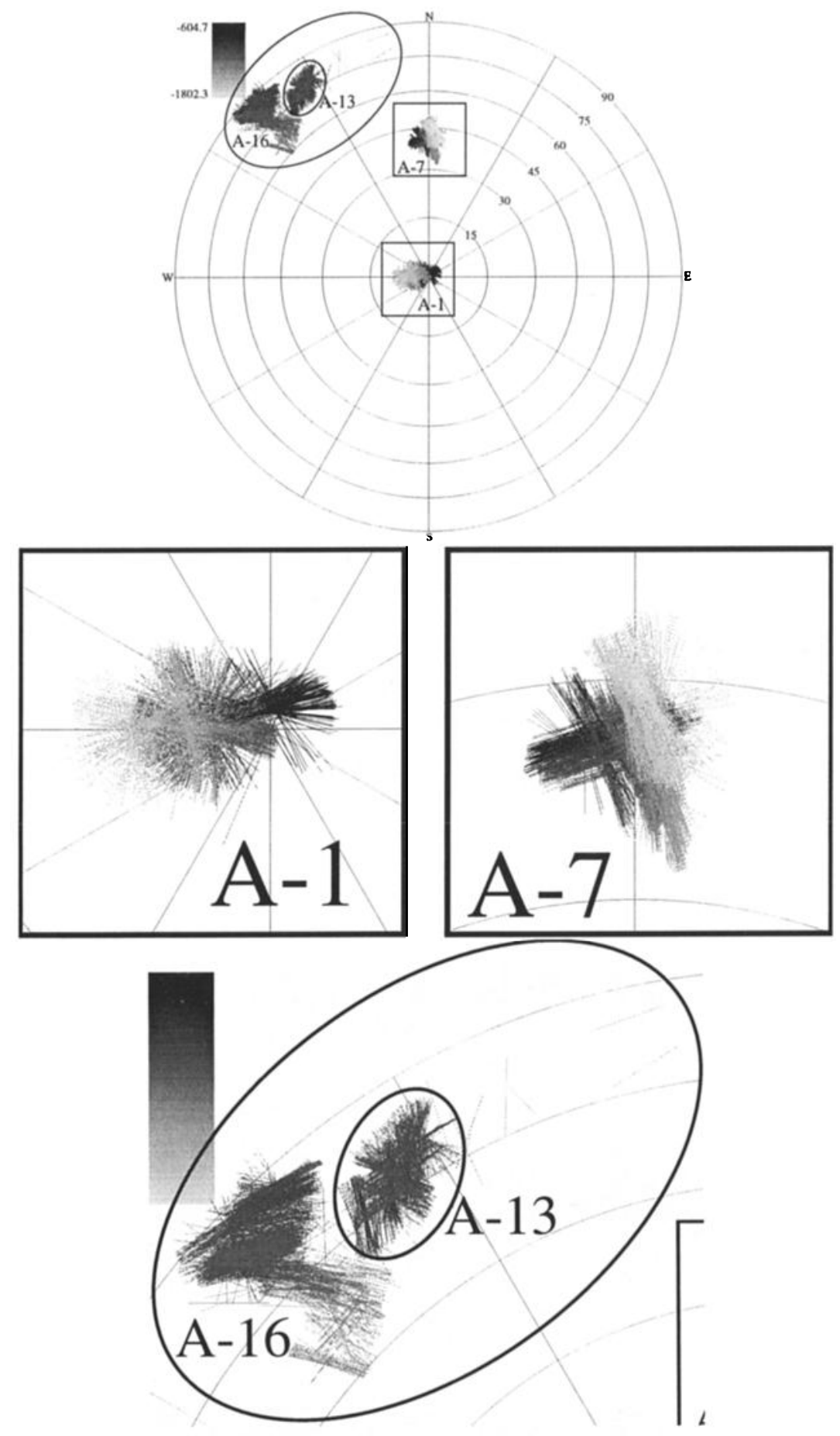

Figure 11. Lower hemisphere stereographic projection plots of the azimuth of borehole elongation at $1 \mathrm{~m}$ log depth intervals from the hour wells drilled in the Point Pedernales field. (top) Lower hemisphere with all the well data plotted. (bottom) Enlargements of the top figure. The graduated depth scale shows the true vertical depth in meters.

hole elongation. Also shown are enlargements of certain regions of the plot to better show the borehole elongation directions.

5. Select breakouts from the borehole elongation data, using the breakout selection criteria described above. As an example we show the calibrated caliper and declination-corrected digitized dipmeter data and derived quantities as a function of $\log$ depth with the selected breakouts from well A-1 in Figure 12. Figure 14 shows all of the selected breakouts in the Point Pedernales data. We did not manually remove any breakouts due to key seats from the breakouts selected by computer. Note that no breakouts were found in the data from well A-7 because of the odd character of the data 


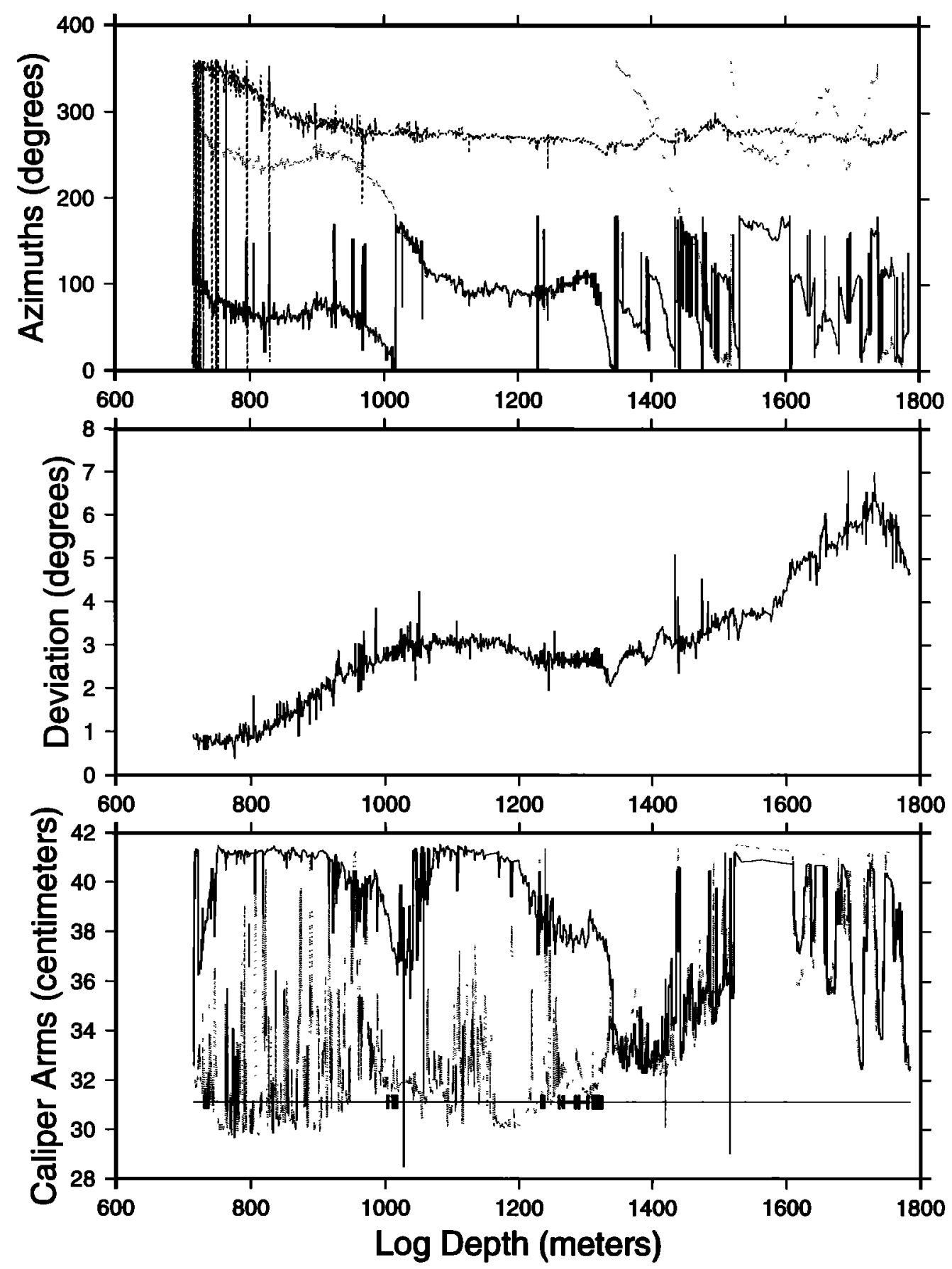

Figure 12. Plots of the caliper-calibrated and declination-corrected digitized dipmeter data and derived quantities as a function of log depth from well A-1. (top) Borehole elongation direction (solid line), pad 1 azimuth (dotted line), and borehole azimuth (dashed line). (middle) Borehole deviation. (bottom) Bit size (straight solid line), caliper arm 1 (solid line), and caliper arm 2 (dotted line). Selected breakout regions are plotted as horizontal bars showing the depth extent of the breakouts.

from the caliper arm, which routinely showed caliper arm diameters quite a bit larger and smaller than the bit size and caused the data to fail at matching criterion 3 described earlier. Since well A-7 was the only well logged with a six-arm dipmeter, the particular technique used to calculate six-arm borehole elongation angles becomes moot.
In Figure 13 we plot a histogram of the angular differences between the location of the high and low sides of the borehole and the breakout angle measured in the plane perpendicular to the borehole axis for all of our selected breakouts. There is roughly a $20^{\circ}$ spread of breakout angles about the high side of the hole. These data show the same clustering of breakout angles near 
Table 3. Characteristics of the Stress State That Minimized the Weighted One-Norm Misfit of the Point Pedernales Borehole Breakout Data

\begin{tabular}{llll}
\hline & $S_{1}$ & $S_{2}$ & $S_{3}$ \\
\hline Azimuth & $\mathrm{N} 148.5^{\circ} \mathrm{E}$ & $\mathrm{N} 55.8^{\circ} \mathrm{E}$ & $\mathrm{N} 318.7^{\circ} \mathrm{E}$ \\
Plunge & $31.5^{\circ}$ & $4.4^{\circ}$ & $58.1^{\circ}$ \\
Value & 2 & $1.821_{1.584}^{1}$ & 1 \\
\hline
\end{tabular}

Optimized $\phi, 0.821_{0.584}^{1.000} ;$ minimum weighted one-norm misfit, $4.84^{\circ} ; 95 \%$ confidence level for weighted onenorm misfit, $5.96^{\circ}$.

the high and low sides of the hole as Qian and Pedersen's [1991] data (Figure 7).

6. Invert the selected breakout data for the best fitting stress state, using the combined GA and Powell optimization technique described above. The results of the inversion are shown in Table 3 . We note that the misfit between the optimized model is $4.84^{\circ}$, more than twice as large as the $1.71^{\circ}$ misfit from the Qian and Pedersen [1991] inversion.

After "inverting" the Point Pedernales data we compare the theoretical breakout pattern with the observations of good quality breakouts (Figure 14). Both the nodal points of the pattern are along a strike of roughly $\mathrm{N} 37^{\circ} \mathrm{W}$, with the near-vertical one plunging $85^{\circ}$ and the near-horizontal one plunging $28^{\circ}$ from horizontal. One nodal point lies between the A-13 and A-16 clusters of breakouts, which have a distinctly different trend. Finally, it should be noted that the nodal points are not symmetric about the origin of the plot, unlike the simple stress state examples shown in Figure 2, because none of the principal stress directions are vertical (Table 3).

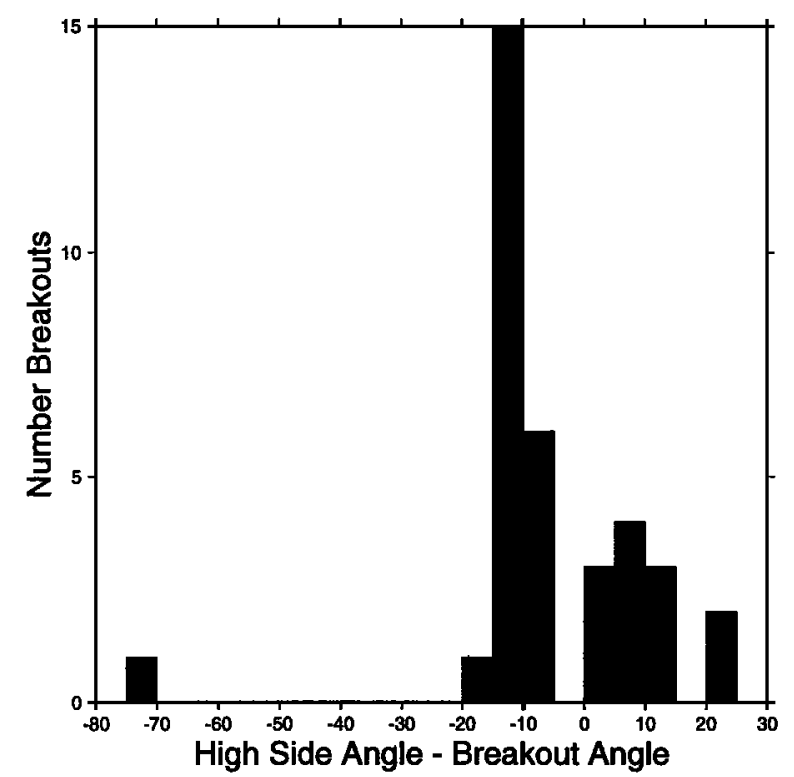

Figure 13. Histogram of the angular difference measured in the plane perpendicular to the borehole axis between the breakout orientation and the high and low sides of the borehole for the Point Pedernales data.
The best fit orientation of the greatest principal stress direction, $S_{1}$, is $\mathrm{N} 148.5^{\circ} \mathrm{E}$, surprisingly more east of south than is to be expected. However, the $95 \%$ confidence levels on the $S_{1}$ direction would permit it to lie in the azimuth range from $\mathrm{N} 143.0^{\circ} \mathrm{E}$ to $\mathrm{N} 198.1^{\circ} \mathrm{E}$ (Figure 15). Given the relative shallowness of the breakout data, the deepest breakout being $1.2 \mathrm{~km}$ deep, the stress state has no principal vertical stress direction. The minimum stress, $S_{3}$, is the closest principal stress direction to vertical, being $31.9^{\circ}$ away from vertical.

This finding does not agree well with the regional breakout, focal mechanism, hydraulic, and geologic data presented by Mount and Suppe [1992], which show horizontal principal stress directions oriented NE-SW. It also does not agree well with the inferred NNW trends of young folds in the Southern Santa Maria Basin [e.g., Clark et al., 1991], which might imply a more NE or ENE direction of $S_{H}$. However, it is possible that the stress state in the Point Pedernales field varies locally from place to place, so that our result may not be regionally representative of the stress field beyond the immediate area of the borehole system studied here.

The stress state $\phi$ ratio is reasonably well constrained by the data we used at the $95 \%$ confidence level (Figure 16). This finding is in contrast to the Qian and Pedersen [1991] data, which were unable to constrain the stress ratio $\phi$. The notable difference here is due to the location of the breakout nodal points, one of which is well constrained in the Point Pedernales data by the difference in breakout orientation between the wells A13 and A-16. Although we used all the data we could obtain from this drilling platform, we recognize that use

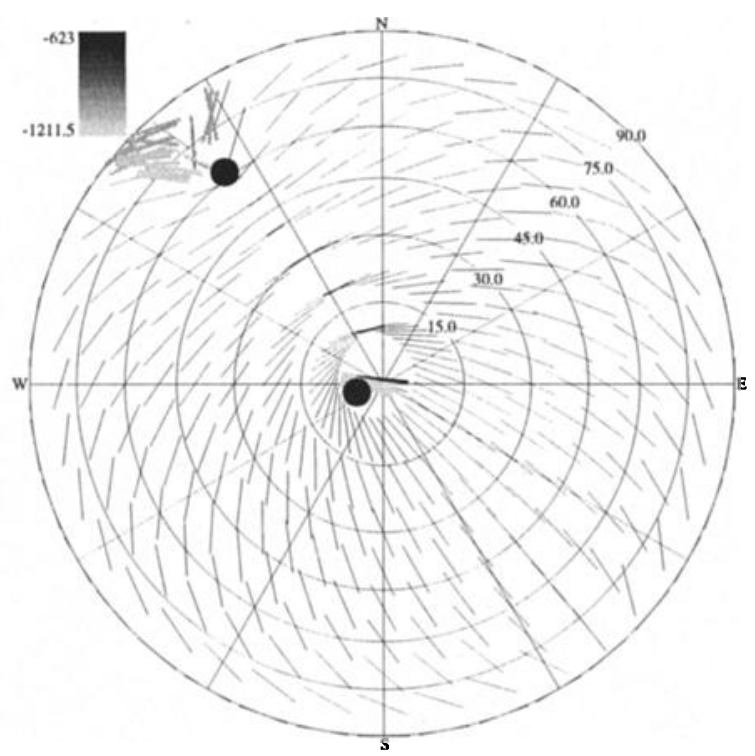

Figure 14. Lower hemisphere stereographic projection plot of the selected Point Pedernales breakouts plotted on top of the theoretical breakout pattern of the best fitting stress state. The graduated scale shows the depth of the selected breakouts in meters. The two solid circles are the location of the nodal points of the theoretical breakout pattern. 


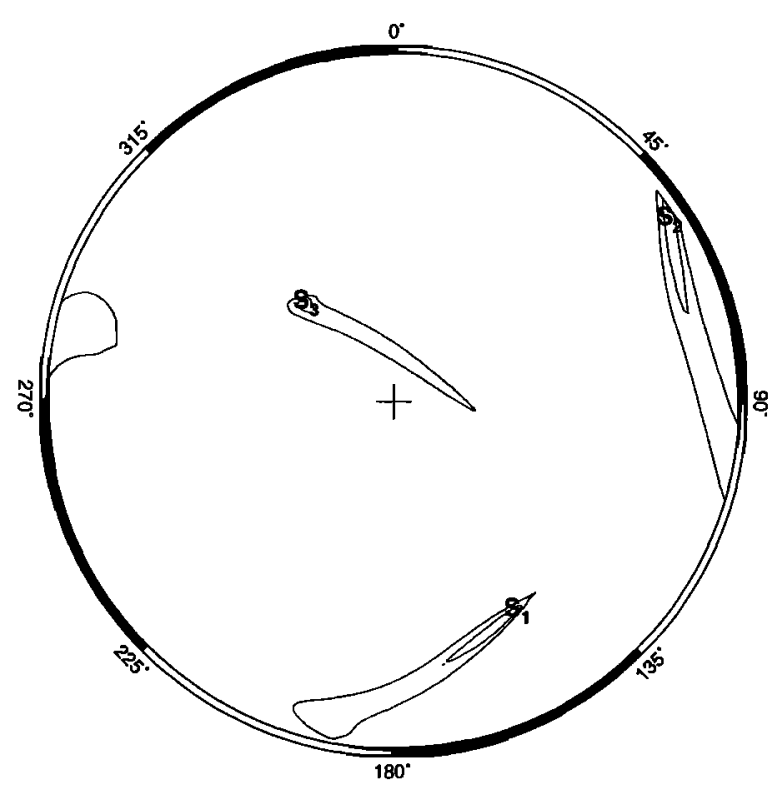

Figure 15. Lower hemisphere stereographic projection plot of orientations of the principal stress directions of the best fitting stress state. The inner and outer contours are the $75 \%$ and $95 \%$ confidence limits for the each principal stress direction. The stress state $\phi$ ratio was held constant at 0.821 .

of additional data for this region would be preferable in order to better constrain the regional stress state. Obviously, more complete coverage of the borehole orientation space represented by the plot in Figure 14 would allow a better estimation of the overall variability of the measurements and show whether the inferred positions of the nodal points are likely to be correct on a more regional scale.

\section{Conclusion}

We developed a technique using genetic algorithms and a Powell optimizer whereby borehole breakout data from variably deviated boreholes are used to constrain the orientation of the principal stress directions and their relative magnitudes. Some of the advantages of GAs are that they efficiently search the problem space, do not require a good starting model, do not get trapped in local minima (unlike gradient search methods), and only require a forward modeling calculation of the misfit between the theoretical breakouts for a model and the data. However, as demonstrated by our inversion of the Point Pedernales data when the misfit as a function of the model is not smooth, the GA may not find the global minimum, requiring many runs of the GA and Powell optimizer to ensure that a reasonable minimum was found. We use a calculation inspired by Gephart and Forsyth [1984] to determine the 95\% confidence limit on a weighted misfit between a particular model and the data. We then place $95 \%$ confidence limits on the results of an inversion by searching the model space around the best fitting model for model misfits that lie at the $\mathbf{9 5 \%}$ confidence limit.

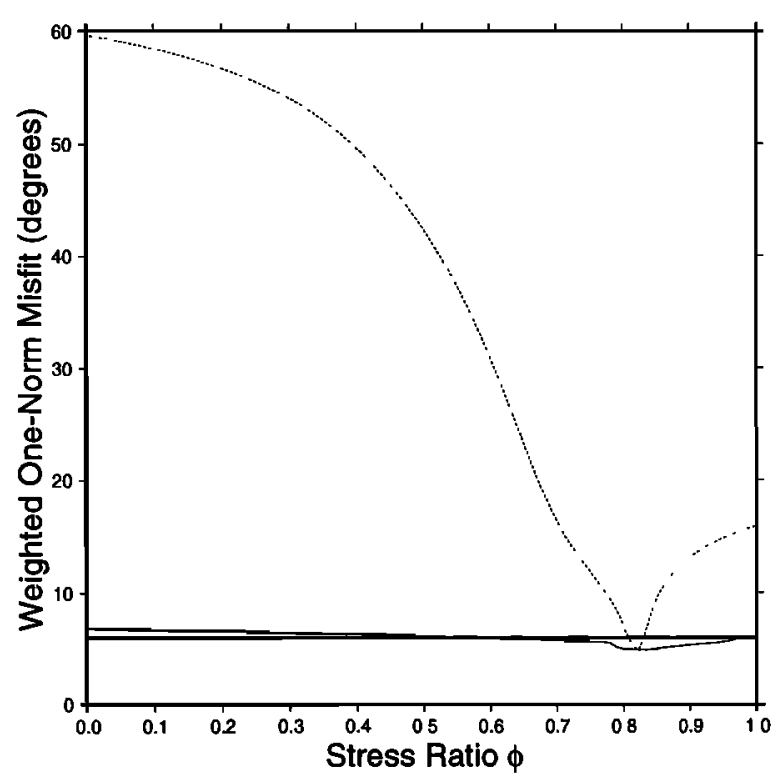

Figure 16. Plot of the weighted one-norm misfit for the Point Pedernales data as a function of $\phi$, where the thick solid line is the $95 \%$ confidence limit $\left(5.96^{\circ}\right)$, the thin solid line is the minimized misfit when $\phi$ is held constant and the principal stress directions are unconstrained, and the dotted line is the misfit using the principal stress directions from the best fitting model.

In processing our raw dipmeter data we developed a modified list of borehole breakout selection criteria based on Plumb and Hickman's [1985] criteria. The main difference between their criteria and ours is that we do not discard radial breakouts, since theoretical breakout patterns show that there are borehole orientations in which radial breakouts are expected for most stress states.

If the regional stress state is either normal or thrust faulting, then the breakout pattern nodal points are likely to be found at low borehole deviations, resulting in a good determination of the principal stress directions and the stress state $\phi$ ratio. If the regional stress state is strike-slip or has a large amount of strike-slip faulting in it, then highly deviated boreholes are required to constrain the stress tensor.

We applied our technique to the Qian and Pedersen [1991] breakout data, where we showed that removing the constraint of a vertical principal stress direction lowered the total misfit between the best fitting model and the data. The Qian and Pedersen [1991] inversion falls outside the $95 \%$ confidence limits found on our solution. However, our determination of the horizontal maximum principal stress direction agreed with Qian and Pedersen's [1991] result to within $1.6^{\circ}$. The data also showed an unconstrained $\phi$ ratio, since the borehole orientations did not vary sufficiently to locate a nodal point in the breakout pattern.

Finally, we inverted a breakout data set from the offshore Santa Maria Basin, California, and determined that the maximum principal stress direction is oriented $\mathrm{N} 148.5^{\circ} \mathrm{E}$ and plunges $31.5^{\circ}$. The $95 \%$ confidence lim- 
its on the $S_{1}$ azimuth are $\mathrm{N} 143.0^{\circ} \mathrm{E}$ to $\mathrm{N} 198.1^{\circ} \mathrm{E}$. The inversion also yielded a stress state in which none of the principal stresses are vertical. The $S_{3}$ direction is the principal stress closest to vertical, making a $31.9^{\circ}$ angle away from vertical. This is a highly nonvertical stress for being within $1.2 \mathrm{~km}$ of the surface.

Because of the highly variable borehole azimuths and deviations of wells drilled from offshore platforms and because oriented caliper data are generally recorded for such wells, a large quantity of data probably exist that can be inverted by using our technique. If more detailed borehole imaging is available to constrain breakout orientations (e.g., formation microimaging, borehole televiewer), this technique can also be applied with a higher degree of confidence regarding the quality of breakouts used in the analysis.

Acknowledgments. The authors thank Julie Shemeta for providing a lot of help with this work, Jerry Lohr for releasing the Santa Maria data to us, and Torch Operating Company for allowing us to publish the data. We acknowledge Leonid Germanovich, Bezalel Haimson, and Pavel Peška for their constructive reviews of this paper. We also thank Wessel and Smith [1995] for creating the GMT plotting tools. This work was supported by the National Earthquake Hazards Reduction Program of the U.S. Geological Survey (USGS) and by NSF grant EAR-9296102 for J. M. Stock. Research was supported by the USGS, Department of the Interior, under USGS award 1434-93-G-2297. The views and conclusions contained in this document are those of the authors and should not be interpreted as necessarily representing the official policies, either expressed or implied, of the U.S. government. Caltech Seismological Laboratory Contribution Number $\mathbf{5 7 2 9}$.

\section{References}

Aadnoy, B. S., Inversion technique to determine the in-situ stress field from fracturing data, J. Pet. Sci. Eng., 4, 127141, 1990a.

Aadnoy, B. S., In-situ stress direction from borehole fracture traces, J. Pet. Sci. Eng., 4, 143-153, 1990 b.

Bell, J. S., and D. I. Gough, Northeast-southwest compressive stress in Alberta: Evidence from oil wells, Earth Planet. Sci. Lett., 45(2), 475-482, 1979.

Bell, J. S., and D. I. Gough, The use of borehole breakouts in the study of crustal stress, in Hydraulic Fracturing Stress Measurements, edited by M. D. Zoback and B. C. Haimson, pp. 201-209, Nat. Acad. Press, Washington, D. C., 1983.

Brent, R. P., Algorithms for Minimization Without Derivatives, Prentice-Hall, Englewood Cliffs, N. J., 1973.

Clark, D. H., N. T. Hall, D. H. Hamilton, and R. G. Heck, Structural analysis of late Neogene deformation in the Central Offshore Santa Maria Basin, California, J. Geophys. Res., 96(B4), 6435-6457, 1991.

Crouch, J. K., S. B. Bachman, and J. T. Shay, Post Miocene compressional tectonics along the Central California Margin, in Tectonics and Sedimentation Along the California Margin: Pacific Section S.E.P.M., vol. 38, edited by J. K. Crouch and S. B. Bachman, pp. 37-54, Soc. of Econ. Paleontol. and Mineral., Tulsa, Okla., 1984.
Daneshy, A. A., A study of inclined hydraulic fractures, $J$. Soc. Pet. Eng., 13, 61-68, 1973.

Davis, L. (Ed.), Genetic Algorithms and Simulated Annealing, Morgan Kaufmann, San Francisco, Calif., 1987.

Fairhurst, C., Methods of determining in situ rock stresses at great depths, Tech. Rep. TRI-68, Mo. River Div. Corps of Eng., Omaha, Neb., 1968.

Gephart, J. W., and D. W. Forsyth, An improved method for determining the regional stress tensor using earthquake focal mechanism data: Application to the San Fernando Earthquake sequence, J. Geophys. Res., 89(B11), 9305-9320, 1984.

Goldberg, D. E., Genetic Algorithms in Search, Optimization, and Machine Learning, Addison-Wesley, Reading, Mass., 1989.

Goldstein, H., Classical Mechanics, 2nd ed., AddisonWesley, Reading, Mass., 1950.

Gough, D. I., and J. S. Bell, Stress orientation from oil-well fractures in Alberta and Texas, Can. J. Earth Sci., 18(3), 638-645, 1981.

Hiramatsu, Y., and Y. Oka, Stress around a shaft or level excavated in ground with a three-dimensional stress state, Mem. Fac. Eng., Kyoto Univ., 24, 56-76, 1962.

Hobbs, B. E., W. D. Means, and P. F. Williams, An Outline of Structural Geology, John Wiley, New York, 1976.

Holland, J. H., Adaptation in Natural and Artificial Systems, Univ. of Mich. Press, Ann Arbor, 1975.

Hubbert, M. K., and D. G. Willis, Mechanics of hydraulic fracturing, J. Pet. Technol., 9(6), 153-168, 1957.

Jaeger, J. C., and N. G. W. Cook, Fundamentals of Rock Mechanics, 3rd ed., Chapman and Hall, New York, 1979.

Kirsch, G., Die Theorie der Elastizität und die Defurfnisse der Fertigkeirslehre, VDI Z., 42, 797, 1898.

Mardia, K. V., Statistics of Directional Data, Academic, San Diego, Calif., 1972.

Mastin, L., Effect of borehole deviation on breakout orientations, J. Geophys. Res., 93(B8), 9187-9195, 1988.

McCrory, P. A., D. S. Wilson, J. C. Ingle, and R. G. Stanley, Neogene geohistory analysis of Santa Maria Basin, California, and its relationship to transfer of central California to the Pacific plate, U.S. Geol. Surv. Bull., 1995-J, 1995.

McCulloch, D. S., Regional geology and hydrocarbon potential of offshore central California, in Geology and Resource Potential of the Continental Margin of Western North America and Adjacent Ocean Basins: Beaufort Sea to Baja California, vol. 6, Earth Sci. Ser., edited by D. W. Scholl, A. Grantz, and J. G. Vedder, chap. 16, pp. 353401, Circum-Pac. Counc. for Energy and Miner. Resour., Houston, Tex., 1987.

Moos, D., and M. D. Zoback, Utilization of observations of well bore failure to constrain the orientation and magnitude of crustal stresses: Application to continental, Deep Sea Drilling Project and Ocean Drilling Project boreholes, J. Geophys. Res., 95(B6), 9305-9325, 1990.

Mount, V. S., and J. Suppe, Present-day stress orientations adjacent to active strike-slip faults: California and Sumatra, J. Geophys. Res., 97(B8), 1995-2013, 1992.

Parker, R. L., and M. K. McNutt, Statistics for the onenorm misfit measure, J. Geophys. Res., 85(B8), 44294430, 1980.

Peška, P., and M. D. Zoback, Compressive and tensile failure of inclined well bores and determination of in-situ stress and rock strength, J. Geophys. Res., 100(B7), 12,791$12,811,1995$.

Plumb, R. A., and S. H. Hickman, Stress-induced borehole elongation: A comparison between the four-arm dipmeter and the borehole televiewer in the Auburn Geothermal well, J. Geophys. Res., 90(B7), 5513-5522, 1985.

Qian, W., and L. B. Pedersen, Inversion of borehole breakout orientation data, J. Geophys. Res., 96(B12), 20,093- 
20,107, 1991. (Correction, J. Geophys. Res., 99(B1), 707710, 1994).

Richardson, R. M., Hydraulic fracture in arbitrarily oriented boreholes: An analytic approach, in Hydraulic Fracturing Stress Measurements, edited by M.D. Zoback and B.C. Haimson, pp. 167-175, Natl. Acad. Press, Washington, D.C., 1983.

Sorlien, C. C., Structure and Neogene evolution of the Southern offshore Santa Maria Basin and Western Santa Barbara Channel, California, Ph.D. thesis, Univ. of Cailf., Santa Barbara, 1994.

Stock, J. M., J. H. Healy, S. H. Hickman, and M. D. Zoback, Hydraulic fracturing stress measurements at Yucca Mountain, Nevada, and relationship to the regional stress field, J. Geophys. Res., 90(B10), 8691-8706, 1985.

Timoshenko, S., and J. Goodier, Theory of Elasticity, McGraw-Hill, New York, 1970.

Vernik, L., and M. D. Zoback, Estimation of maximum horizontal principal stress magnitude from stress-induced well bore breakouts in the Cajon Pass Scientific Research Borehole, J. Geophys. Res., 97(B4), 5109-5119, 1992.

Wessel, P., and W. H. F. Smith, New version of the generic mapping tools released, EoS Trans. AGU Electron. Suppl., Aug. 15, 1995. (Available as http://www.agu.org/eos_elec/95154e.html).

Youngdahl, C. K., and E. Sternberg, Three-dimensional stress concentration around a cylindrical hole in a semiinfinite elastic body, J. Appl. Mech., 33, 855-865, 1966.
Zajac, B., and J. M. Stock, Using borehole breakouts to constrain the complete stress tensor (abstract), EoS Trans. $A G U, 73(43)$, Fall Meet. Suppl., 559, 1992.

Zemanek, J., E. E. Glenn, L. J. Norton, and R. L. Caldwell, Formation evaluation by inspection with the borehole televiewer, Geophysics, 35(2), 254-269, 1970.

Zoback, M. D., and J. H. Healy, In situ stress measurements to $3.5 \mathrm{~km}$ depth in the Cajon Pass Scientific Research Borehole: Implications for the mechanics of crustal faulting, J. Geophys. Res., 97(B4), 5039-5057, 1992.

Zoback, M. L., 1st-order and 2nd-order patterns of stress in the lithosphere: The World Stress Map Project, $J$. Geophys. Res., 97(B8), 1703-1728, 1992.

Zoback, M. L., and M. D. Zoback, State of stress in the conterminous United States, J. Geophys. Res., 85(B11), 6113-6156, 1980.

Zoback, M. L., et al., Global patterns of intraplate stress: A status report on the world stress map project of the International Lithosphere Program, Nature, 341 (6240), 291-298, 1989.

J.M. Stock, and B.J. Zajac, Seismological Laboratory, California Institute of Technology, Pasadena, CA, 91125. (e-mail: jstock@gps.caltech.edu; blair@gps.caltech.edu)

(Received August 5, 1996; revised November 19, 1996; accepted December 11, 1996.) 